\title{
O Afro-Brasileiro e o Debate Sobre o Sistema de Cotas: Um Enfoque Psicossocial
}

The Afro-Brazilian and the debate on the quotas system:

A psychosocial view

Ricardo Franklin

Ferreira \& Ricardo

Mendes Mattos

Universidade

São Marcos

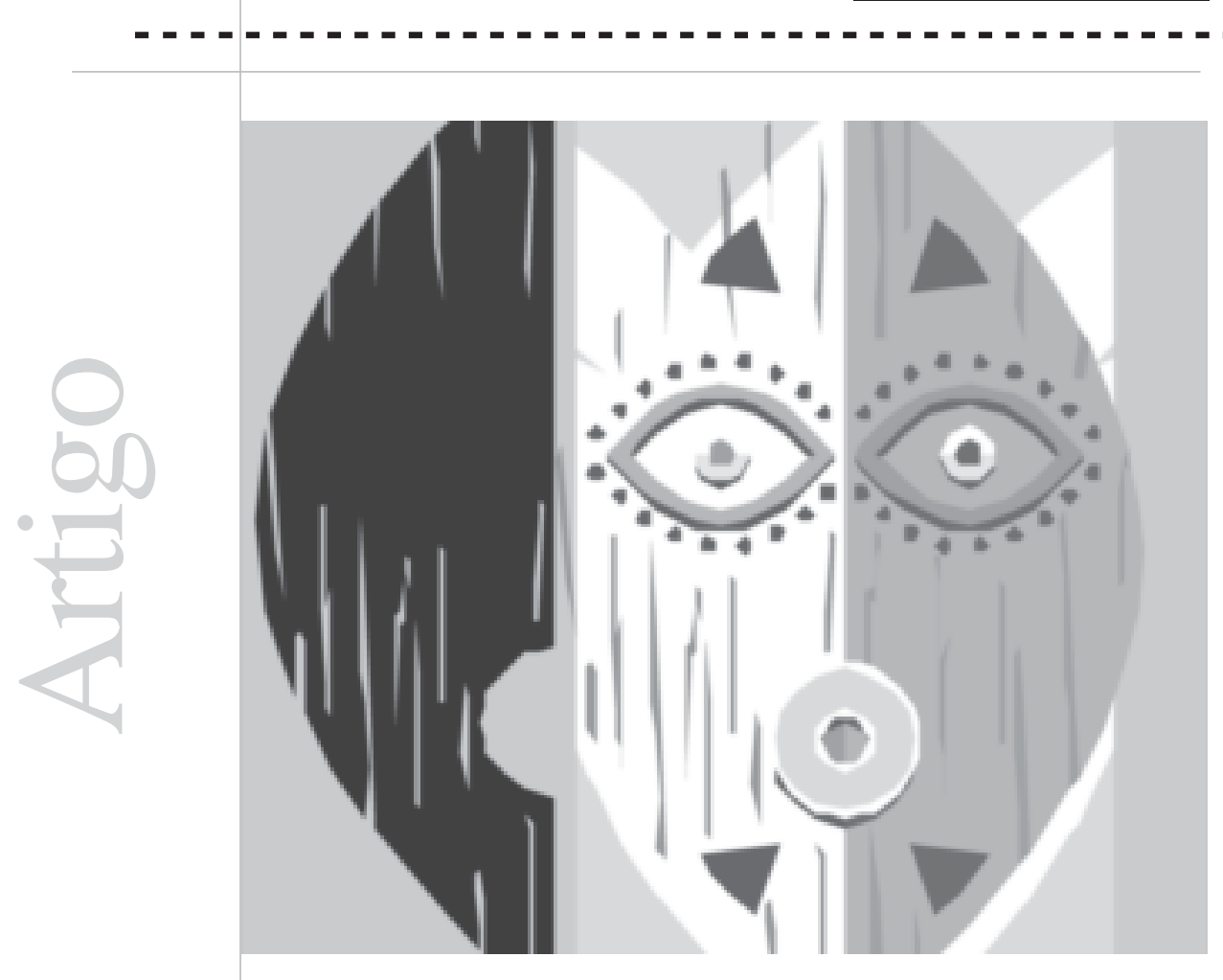




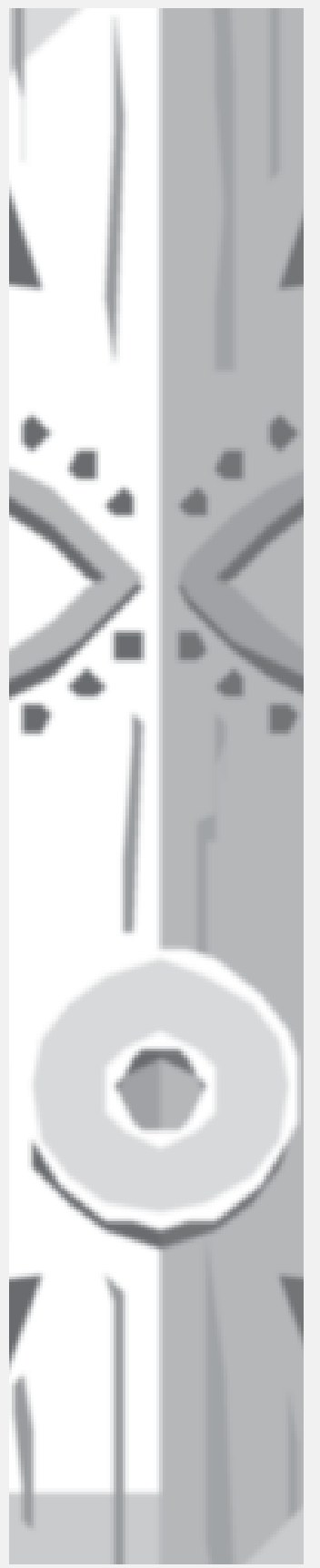

Resumo: Tendo como base o debate sobre o sistema de cotas para negros nas universidades públicas, o presente artigo tem por objetivo explicitar os vários argumentos que configuram o campo de discussões acerca da implantação desse sistema, que constitui uma forma de ação afirmativa, visando a possíveis efeitos favoráveis dessa medida para o processo de construção da identidade do afro-brasileiro. Para tanto, recorreu-se à análise de diversos artigos e matérias publicadas pela imprensa escrita. Verificou-se a concentração dos debates, tanto das pessoas favoráveis ou contrárias às cotas, em seis esferas: ético/jurídica, étnica, político/assistencial, ideológica, pedagógica e das relações raciais. Por fim, concluiu-se que o debate sobre o sistema de cotas inaugura uma fase de discussões mais explícitas sobre as questões raciais, o que favorece a transformação do afro-descendente no sentido de atuar de forma crítica e emancipatória na conquista de seus direitos.

Palavras-chave: afro-brasileiro, sistema de cotas, identidade, ações afirmativas, emancipação humana.

Abstract: Based on the discussion about the quotas system for black descendents in the public University, the current article intends to explicit the large amount of arguments that are part of this field on the implementation of this issue, which is a positive way of action, having in mind possible and favorable effects to impose and to construct the AfroBrazilian identity. In order to achieve this, several articles and pressreleased material were analyzed. This debate was focused and concentrated either on the favorable and opponent people, in six topics: ethic/judgemental, ethnical, political/assistance, ideological, pedagogical and racial relations. In this matter, the conclusion is that the quotas system debate initiates a new phase of explicit discussion on the racial issue, pushing the afrodescendents to assign a critical and emancipated way to conquer their rights.

Key words: Afro-Brazilian, quotas system, identity, affirmative actions, human emancipation. 
Alunos, educadores, políticos, pesquisadores, líderes de movimentos sociais, representantes de organizações da sociedade civil, reitores, jornalistas - diversos personagens e uma só discussão: o sistema de cotas para afrodescendentes nas universidades públicas. Tal discussão, muito longe de consensual, é permeada por opiniões divergentes. Vantagens e desvantagens desse sistema são amplamente analisadas com base em concepções diversas. Entretanto, uma faceta desse debate é indubitável: a promoção de um diálogo aberto sobre as questões relacionadas aos afrodescendentes, que tende ao rompimento com a dissimulada idéia de uma "democracia racial" no Brasil.

Essa polêmica instigou este trabalho. Tendo como base referências da Psicologia social e das ciências sociais, partiu-se do contexto histórico que gestou o afro-brasileiro e das condições concretas às quais essa população está submetida hoje. Tais condições determinam efeitos negativos na construção das identidades pessoais que, por sua vez, participam da construção de todo o tecido social, através de um processo dialético contínuo que tende, num círculo vicioso, a manter as desigualdades, em função de um racismo institucionalizado, processo analisado com muita propriedade por Santos (2001).

As várias discussões, voltadas para a questão das cotas para os afro-descendentes nas universidades, articulam-se em torno de aspectos jurídicos, políticos, de relações raciais, do problema da exclusão social do brasileiro e da falta de qualidade das escolas públicas, dentre outros. Entretanto, os argumentos que permeiam as discussões somente tangenciam os possíveis efeitos da política de cotas na construção da subjetividade do afrodescendente e da sua inserção como sujeito histórico de transformação da realidade social que o constituiu.

Esse contexto serviu de terreno para, como objetivo do trabalho, explicitar os vários argumentos que configuram o campo de discussões acerca da implantação do sistema de cotas, uma forma de ação afirmativa.

Para isso, analisamos alguns artigos de jornais e revistas de grande circulação nacional, como O Estado de São Paulo, Folha de São Paulo, Jornal da Tarde, o Correio Braziliense e a revista Época, além de outros disponíveis na internet, através do procedimento abaixo descrito.

Consideramos artigos escritos a partir de agosto de 2001. Após sua classificação em seis esferas de debate que configuram o campo de discussões (esfera ético/jurídica, esfera étnica, esfera político/assistencial, esfera ideológica, esfera pedagógica e esfera das relações raciais, definidas no item 5), foram analisados os conteúdos ali contidos até que se tornassem saturados, isto é, até o momento em que as informações se tornaram repetitivas. Dessa maneira, foram utilizados trinta e quatro artigos que representam a amostra do universo de cento e vinte e dois trabalhos consultados e que também possibilitaram discorrer sobre as seis esferas de debate.

Decidimos analisar artigos veiculados em jornais e revistas, por considerarmos a importância da imprensa escrita como meio de comunicação sobre o assunto. Alinhados com Guareschi (2004), podemos dizer que essa comunicação, hoje, constrói a realidade, pois "a mídia tem, na contemporaneidade, o poder de instituir o que é ou não real, existente” (p. 83), além de dar uma conotação valorativa à realidade. Assim, as opiniões expressas pela mídia não somente reproduzem como também formam as representações sociais constituintes de uma certa cultura. Representações sociais são aqui entendidas, conforme Jodelet (2001), como uma forma de conhecimento socialmente elaborado que contribui para a construção de uma realidade comum a um grupo social. 


\section{O afro-brasileiro}

Compreender qualquer processo humano que se dá em um determinado período histórico implica compreender o próprio processo histórico que o constituiu.

Assim, para um trabalho que tem por objetivo configurar o campo de discussões acerca do sistema de cotas para negros na universidade, faz-se necessário compreendê-lo como parte de um conjunto de condições expresso através da vida material, social e política desenvolvida historicamente pelo povo negro no Brasil.

O Brasil foi o país americano a escravizar o maior número de africanos (a partir de 1538), e o último do mundo cristão a abolir a escravidão, só o fazendo devido à pressão exercida pela Inglaterra ao modelo vigente na época (Moura, 1988). Sua história inicia-se num cenário mercantil, baseado num sistema escravagista, sustentáculo da mão de obra do País por cerca de quatro séculos.

Tal período foi seguido por dois acontecimentos concomitantes, a Abolição e a imigração de europeus para a substituição da mão de obra escrava, que intensificaram as dificuldades na vida do afro-brasileiro, com sua peregrinação em busca de sobrevivência, sem condições de competir no mercado de trabalho com os imigrantes que passaram a fazer parte do novo cenário.

Em 1888, com a Abolição, podemos imaginar quantos africanos escravizados deixaram as senzalas, sonhando com melhores dias, com a esperança de que, a partir da assinatura da Lei Áurea, passariam a ter os mesmos direitos de todos os brasileiros.

Porém, não foi o que aconteceu. Apesar de o Brasil ser um país que se declara de democracia racial, não foi tomada nenhuma medida para cuidar de sua grande população de ex-escravos e de seus descendentes, em sua maioria pobres e com pouca instrução formal. Para
Suplicy (2002), a abolição das leis escravistas não significou, para os escravos, uma libertação. Foram lançados num mercado despreparado para receber esse imenso contingente, e os afro-brasileiros passaram a ser ainda mais desassistidos. Para esse autor, até os dias atuais, os afro-brasileiros são a maioria da população que habita as favelas, os vãos de viadutos, está nas filas de emprego, nas portas dos hospitais públicos, nos presídios e sofre por questões ligadas a um profundo preconceito racial ${ }^{1}$.

Fruto desse processo histórico na formação do brasileiro, a desqualificação sistemática dos afro-descendentes, apesar de personagens fundamentais na construção e no desenvolvimento do País, levou à veiculação de representações sociais articuladas a valores, crenças e sentimentos negativos a respeito dos membros desse grupo em diversas esferas da vida social, como no trabalho e na educação. Em outras palavras, foram criadas referências estigmatizantes de ordem física, intelectual e social associadas à pessoa negra. Essas referências passaram a ser socialmente legitimadas, tornando-se 'verdades' compartilhadas e difundidas pela maioria da população. Tal processo levou os afrodescendentes a vivenciarem situações de humilhação e desprestígio pessoal, que vieram a desencadear as desvantagens por eles enfrentadas nas situações concretas do dia a dia (Ferreira, 2000; Ferreira, 2002; Ferreira e Camargo, 2001; Larkin Nascimento, 2003).

Na sociedade brasileira, apesar de já questionado, ainda hoje persiste o mito da democracia racial, que permanece encobrindo, de maneira perversa, a discriminação racial. Munanga (1999) argumenta acerca dessa temática dizendo que "o mito da democracia racial tem como base a dupla mestiçagem biológica e cultural entre as três raças originárias. Exalta a idéia de convivência harmoniosa entre os indivíduos de todas as camadas sociais e os grupos étnicos” (p. 80). Tal crença favorece a dissimulação das desigualdades pelas elites dominantes e
1 Preconceito é aqui considerado um julgamento negativo de valor em relação a uma pessoa, não espontâneo $e$ nem hereditário, destituído de base objetiva e construído culturalmente, e pertence à classe de mitos desenvolvidos através da socialização. 
...o brasileiro negro, cuja vivência se encontra associada a baixos salários, a profissões consideradas de menor valia, à baixa escolaridade e a um status social considerado inferior, tende a construir uma identidade associada a valores negativos, com uma decorrente baixa auto-estima pessoal. impede que os membros das comunidades não-brancas tenham consciência dos sutis mecanismos de exclusão dos quais são vítimas.

Assim, tal mito reduz as possibilidades de as comunidades negras tomarem consciência de suas especificidades culturais, o que vem dificultar a construção e expressão de uma identidade própria. Além disso, como analisa Bernardino (2002), da idéia de democracia racial, associada à popularidade do ideal de branqueamento, derivam as dificuldades de as pessoas se classificarem como negras no Brasil.

Nesse contexto, historicamente construído, a pessoa negra desde cedo "aprendeu", através de mecanismos eficazes de reprodução ideológica, que a identidade positivamente afirmada é a do "branco", e o que lhe cabe é a imitação do "ideal”, para poder ser socialmente aceita. Incorporou, reproduziu e continua reproduzindo "verdades brancas”, dentre elas, as que afirmam que o negro é preguiçoso e tem inteligência inferior, como denuncia Bento (2000). Essa visão é expressão do imaginário coletivo, que está presente nas representações sociais dos brasileiros e é usada para justificar as condições socioeconômicas desfavoráveis para a população afro-brasileira, sendo a ela atribuída a responsabilidade por seu fracasso. Dessa forma, conforme Souza (1991), no contexto brasileiro, em que o ideal de ego é ser "branco"; cabe, portanto, ao afrodescendente, a negação de suas origens africanas e a busca de um ideal inatingível: a branquitude.

Assim, torna-se muito difícil para o afrodescendente lidar com as circunstâncias de seu cotidiano. Primeiro, há uma luta interna para aceitar-se como um afro-descendente, ou seja, aceitar-se numa sociedade que o estigmatiza, decorrendo daí uma outra luta: a de exercer sua cidadania e conseguir melhores condições concretas de existência.
Numa realidade dessas, torna-se difícil a construção de uma identidade positivamente afirmada por parte dos afro-descendentes, e, em decorrência, o desenvolvimento de políticas efetivas voltadas para a melhoria de sua qualidade de vida, já que a maioria da sociedade compartilha dessas crenças.

Toda experiência psicológica encerra um caráter de construção permanente, em que as especificidades das experiências pessoais determinam a maneira pela qual as referências de mundo são construídas, incluindo aquelas através das quais alguém pode reconhecer-se como um determinado indivíduo - a identidade. São referências coletivamente compartilhadas em torno das quais a pessoa organiza a si mesma e sua relação com o mundo.

Com base na visão de Berger e Luckmann (1999), consideramos a identidade pessoal um elemento-chave da realidade subjetiva da pessoa. Tal referência permite que ela se sinta autora de sua própria vida, expressão de sua relação dialética com a sociedade, e que tende a ser mantida pelas relações sociais. No caso do afro-brasileiro, essas relações, objetivadas no acervo cultural brasileiro, expressam uma associação de menos valia entre a pessoa negra e os processos valorizados em nossa cultura, como o trabalho e a escolaridade, conforme apontam os índices que veremos a seguir.

Assim, o brasileiro negro, cuja vivência se encontra associada a baixos salários, a profissões consideradas de menor valia, à baixa escolaridade e a um status social considerado inferior, tende a construir uma identidade associada a valores negativos, com uma decorrente baixa auto-estima pessoal. Tal associação, veiculada socialmente, com a decorrente condição psicológica, dificulta a possibilidade de estratégias de enfrentamento, por parte da pessoa negra, no sentido de reverter tal situação, mantendo o círculo vicioso do racismo no Brasil (Santos, 2001). 


\section{Condições de vida do afro- brasileiro: decorrências históricas}

Para ampliarmos nossa compreensão, alguns dados demonstram uma situação de reiterada desigualdade para as pessoas negras, de ambos os sexos, com relação às pessoas brancas, em todos os índices sociais analisados.

No que se refere ao Índice de Desenvolvimento Humano (IDH), o Relatório do Desenvolvimento Humano de 2003, editado anualmente pelo Programa das Nações Unidas para o Desenvolvimento (PNUD), revela que a população negra brasileira possui qualidade de vida notadamente inferior à população branca cinqüenta posições abaixo (Paixão, 2003).

Quanto às condições de trabalho, há uma reiterada desigualdade para os trabalhadores negros, independentemente das regiões brasileiras estudadas. As taxas de desemprego são superiores para os indivíduos de raça negra, não importa qual seja o atributo pessoal considerado. Os índices encontrados foram os seguintes: $6,6 \%$ de brancos e $7,7 \%$ de negros desempregados, fato que tem incidência direta sobre as condições de vida das famílias (DIEESE, 1999). Mesmo considerando a população trabalhadora, os rendimentos dos trabalhadores negros são sistematicamente inferiores aos dos demais, quaisquer que sejam as situações ou atributos considerados - conforme dados do DIEESE (1999) e INSPIR/DIEESE (1999, apud Larkin Nascimento, 2000).

Comparando-se o rendimento médio familiar per capita, conforme informações da PNAD/ 2001, de todo o Brasil, em 2001, a população branca recebia salários 196\% maiores em relação às famílias negras. Diante dessa situação, as crianças tendem a deixar de estudar para ajudar no complemento da renda. Assim, para os jovens negros, o ingresso no mercado de trabalho é mais precoce, o que certamente significa prejuízos à sua formação educacional, expressos em números crescentes de jovens que abandonam os estudos para dedicar-se somente ao trabalho, conforme aumenta sua faixa etária. Há uma forte pressão para que isso aconteça em função das dificuldades de sobrevivência das famílias negras (DIEESE, 1999).

Além disso, há, entre a população negra, maior proporção de trabalhadores em funções socialmente qualificadas como de menor valor, em atividades de execução e de apoio a serviços gerais.

Assim, alinhados com Telles (2003), podemos dizer que a raça tem especial importância na formação das desigualdades socioeconômicas no Brasil. As pessoas brancas compõem a vasta maioria das classes média e alta, enquanto as pessoas negras se encontram, de modo desproporcional, em sua maioria, entre os pobres. Essa desigualdade racial, expressa em desigualdade socioeconômica, determina que os negros brasileiros tenham menos chance de chegar a um status econômico mais alto. Quanto à escolaridade, a taxa de analfabetismo entre os afro-brasileiros é mais que duas vezes maior do que entre os brancos (Larkin Nascimento, 2003), ao passo que os primeiros possuem, em média, a metade dos anos de escolaridade destes últimos.

Para Larkin Nascimento (2000), uma criança afro-brasileira tem a chance de cerca de $66 \%$ de obter uma educação básica, ao passo que uma criança branca tem $85 \%$ de chance. A criança afro-brasileira que conseguir completar o ensino básico terá em torno de $40 \%$ de chance de continuar na escola e concluir a educação secundária. Para a criança branca, a chance fica em torno de $57 \%$. Os afrobrasileiros que completam o ensino médio têm aproximadamente metade da chance dos alunos brancos de concluir um curso universitário.

Apesar do aumento gradual do número de pessoas negras que concluem o terceiro grau, 
entre 1960 a 1999, o número de brancos aumentou em ritmo muito mais acelerado. Assim, apesar do aumento da escolaridade da população em geral, nesse período, a desigualdade racial na educação se manteve (Telles, 2003).

Conforme os dados aqui apresentados, apesar de todas essas dificuldades para o jovem negro conseguir completar o curso superior, a discriminação racial se manifesta mais intensamente através dos salários, e, assim, o círculo vicioso se perpetua. Nascer negro está relacionado a maior probabilidade de ser pobre e a menor escolaridade. Essa situação não pode ser tratada como simples herança da escravidão. O racismo é recriado e alimentado a cada dia, e reforça um ciclo cumulativo de desvantagens para a população afro-brasileira. Dessa forma, as manifestações de racismo causam danos materiais, simbólicos, políticos e culturais, que, por vezes, são irreversíveis, principalmente na construção das identidades pessoais dos afro-descendentes.

Tendo em vista essa situação, será possível a criação de ações que possam vir a favorecer a reversão desse ciclo que se retroalimenta?

\section{Ações afirmativas e política de cotas}

Um tipo de estratégia, dentre várias outras, que visa a diminuir os efeitos do racismo, historicamente desenvolvido e mantido pelas práticas sociais ainda vigentes, são as ações afirmativas.

Para Bernardino (2002), ações afirmativas são compreendidas como políticas públicas que têm como objetivo a correção de desigualdades sociais e econômicas decorrentes de discriminação, atual ou histórica, sofrida por determinados grupos de pessoas, como no caso dos afro-descendentes. Trata-se de estratégias que buscam conceder vantagens competitivas para os membros de grupos submetidos a situações de desvantagem e de inferioridade, visando à reversão dessas situações. Assim, “as políticas de ação afirmativa buscam, por meio de um tratamento temporariamente diferenciado, promover a eqüidade entre grupos que compõem a sociedade” (p. 257).

A partir das múltiplas ações do Movimento Negro e da prolongada luta de lideranças negras, verificou-se um dos gestos decisivos para que a discussão sobre ações afirmativas se ampliasse. Conforme Bernardino (2002), foi o reconhecimento público do presidente Fernando Henrique Cardoso de que o País era racista. Isso se deu na abertura do seminário Multiculturalismo e Racismo, realizado em 1996, em Brasília. Além disso, essa discussão foi estimulada, em âmbito nacional, pela divulgação do Programa Nacional dos Direitos Humanos (Presidência da República, 1996), que inclui, dentre seus objetivos, o desenvolvimento de "ações afirmativas para o acesso dos negros aos cursos profissionalizantes, à Universidade e às áreas de tecnologia de ponta”.

Dentre as várias possibilidades de ações afirmativas, uma delas consiste no sistema de cotas, que, conforme definição de Moehlecke (2002), trata-se de uma política que estabelece um “... determinado número ou percentual a ser ocupado em área específica por grupo(s) definidos(s), o que pode ocorrer de maneira proporcional ou não...” (p. 199). Uma das políticas possíveis é o sistema de cotas para negros nas universidades, principal objeto deste estudo.

O sistema de cotas está configurado por diversos dispositivos do Projeto de Lei de Cotas (PL n ${ }^{\circ}$ 73/1999) e do Estatuto da Igualdade Racial (PL no 3.198/2000), que serão submetidos a uma decisão final no Congresso Nacional (Folha de São Paulo, 04/07/2006). O Estatuto da Igualdade Racial, em seu art. 52, estabelece uma cota mínima de $20 \%$ de vagas 
para a população afro-brasileira nos cursos de graduação de todas as universidades de todo o território nacional (Paim, 2003).

Esses Projetos de Lei provocaram reações de vários intelectuais, artistas e integrantes de movimentos sociais, que culminaram em dois manifestos, um contrário à política de cotas Todos têm direitos iguais na República democrática (30/05/2006), com cento e catorze assinaturas, e o outro, Manifesto em favor da Lei de Cotas e do Estatuto da Igualdade Racial (03/07/2006), favorável a essa política, com trezentos e trinta nomes.

\section{Configuração do campo de discussões}

Com o objetivo de traçar uma configuração do campo de discussões, diversas possibilidades se abriram. Dentre elas, talvez a mais simples e de difusão mais vulgar, teríamos a exposição dos argumentos daqueles que são a favor do sistema de cotas em contraposição àqueles que são contra. Dessa forma, porém, faríamos uma análise valorativa e excludente, típica da lógica militante, que nega ou, no mínimo, dá pouca importância à compreensão da diversidade das opiniões bem como do processo envolvido. Tal postura militante - representada pela dinâmica do nós, normalmente donos da verdade, contra o eles, via de regra, vistos como incoerentes e algozes -, colocar-nos-ia mais propícios à discórdia, e não ao diálogo. No entanto, no outro oposto, negando essa contradição entre prós e contras, estaríamos distanciando-nos do verdadeiro campo de discussões que permeia os diversos segmentos da sociedade brasileira atual. Assim, pretendemos nortear nossa exposição em uma postura qualitativamente distinta, demonstrando que diversos argumentos, sejam eles contra ou a favor, trafegam na mesma esfera de debate. Com base nessa postura, teríamos a seguinte configuração do campo de discussões: esfera ético/jurídica, esfera étnica, esfera político/assistencial, esfera ideológica, esfera pedagógica, e, por fim, esfera das relações raciais.

Malgrado apresentadas de forma dicotômica, tais esferas devem ser vistas como partes de uma totalidade - na qual todos esses fatores não são estanques, nem tampouco estáticos, mas interdependentes, em um processo dinâmico de determinação mútua. Assim, apresentando-os separadamente, lançamos mão de uma estratégia de exposição puramente didática.

\section{Esfera ético/jurídica}

A primeira esfera do campo de discussões abrange a interface entre afro-descendentes e brancos, principalmente no que diz respeito à dialética diferença/igualdade. Além dessa interface ética, tal esfera está permeada por discussões de âmbito jurídico, em especial sobre o "princípio de igualdade” em um Estado Democrático de Direito.

Para as pessoas que argumentam contra o sistema de cotas nas universidades públicas brasileiras, observamos discussões em duas direções fundamentais: "inconstitucionalidade" e “discriminação às avessas”.

Primeiramente, ocorre a reincidente afirmação que a medida é inconstitucional, pois fere o princípio de igualdade de direitos, previsto na Constituição brasileira, o que rompe com a premissa de que todos são iguais perante a lei (Chaves, 2001), tese principal na qual se apóia o manifesto contra a política de cotas (Todos têm direitos iguais na República democrática, 2006) e que redunda em uma medida “antidemocrática” (Fernandes, 2003).

Dessa forma, fazem alusão às decisões jurídicas tomadas pela Corte Suprema dos EUA. Esta, desde 1978, tem adotado uma posição voltada para a refutação do elemento raça como determinante no ingresso às universidades, sendo esse aceito somente 


\begin{abstract}
Ele afirma que, com o intuito de promover a igualdade, a medida promove a desigualdade, pois cria privilégios para alguns em detrimento de outros, de forma a gerar uma "discriminação às avessas" LO Estado de São Paulo, 29/ presente na proposta das cotas (Chaves, 2001; Rosenfield, 2006). Ele afirma que, com o intuito de promover a igualdade, a medida promove a desigualdade, pois cria privilégios para alguns em detrimento de outros, de forma a gerar uma "discriminação às avessas" ( $O$ Estado de São Paulo, 29/06/03) ou um "racismo às avessas” (Souza, 2003c). Fala-se, por conseguinte, que a medida repara uma injustiça cometendo outra (Folha de São Paulo, 23/08/01).
\end{abstract} 06/03) ou um "racismo às avessas" (Souza, 2003c). Fala-se, por conseguinte, que a medida repara uma injustiça cometendo outra.

Folha de São Paulo, 23/08/01

Com o intuito de endossar tal prerrogativa, o professor Azevedo (2003) cita alguns efeitos concretos da experiência das cotas no Rio de Janeiro. Segundo esse autor, no caso do curso de desenho industrial da UERJ, somente 11\% das vagas ficaram para aqueles que não se declararam negros ou oriundos das escolas públicas. Tais resultados oferecem ensejo para como um critério parcial em meio a outros (Menezes, 2003).

Um segundo ponto a ser destacado é o argumento que infere a "discriminação" que algumas linhas editoriais declaradamente contra as cotas cheguem mesmo a pronunciarse em termos mais ríspidos, ao afirmarem que essas medidas provocam o oportunismo e acarretam "um racismo às avessas" (Jornal da Tarde, 02/06/03).

No entanto, os argumentos favoráveis às cotas consideram uma posição extremamente hipócrita falar em "igualdade" no interior de uma realidade atual extremamente desigual e injusta para com o afro-descendente.

Os que defendem a desigualdade da situação atual, normalmente, lançam mão da ínfima participação negra na vida universitária, tal como Paulo Sérgio Pinheiro, secretário nacional dos direitos humanos (Chaves, 2001). Nessas circunstâncias, Maria Aparecida da Silva Bento, coordenadora do Centro de Estudos das Relações de Trabalho e Desigualdades, relata que as cotas são $100 \%$ para os brancos, cujos argumentos se baseiam em um "pacto não verbalizado" para manter seus privilégios (Souza, 2003a).

No contexto de desigualdade racial, as cotas constituiriam uma forma de se promover a "igualdade proporcional” por meio de uma "justiça distributiva” de oportunidades iguais a todos (Menezes, 2003). Renato Ferreira, advogado da ONG Educafro, acrescenta que a própria constituição outorga ao Estado o papel de sustentar a igualdade em casos de inequívoca desigualdade (Souza, 2003b).

Segundo o jornalista Fernando Conceição (2002), o sistema atual promove uma falsa impressão de igualdade, pois, na realidade, é desigual, ao tratar em pé de igualdade pessoas que provém de "origens sociohistóricas" desiguais. Dessa forma, longe de ferir o princípio de igualdade, as cotas corrigiriam a aparência dissimulada de igualdade e promoveriam uma igualdade real ou “eqüidade” na competição.

Por fim, há também a afirmação de que as cotas seriam um instrumento de justiça, com o intuito de "ressarcir" a dívida histórica que o Brasil contraiu em relação aos afrodescendentes - como afirma a Presidente de Honra da ONG Fala Preta, Edna Roland (Souza, 2003b). Para Cristovão Buarque, em declaração feita antes de se tornar Ministro da Educação, as cotas seriam um instrumento de “justiça racial e de dignidade nacional”, além de "corrigir a discriminação" e "melhorar a imagem do Brasil no exterior” (Jornal da Tarde, 16/02/03).

Aos que difundem a idéia de que o sistema de cotas seria "antidemocrático", afirma John Payton, advogado americano que representou a Universidade de Michigan na Suprema Corte: "A sociedade deveria estar refletida nas instituições que cria. Esse é o objetivo, se estivermos falando de democracia” (Souza, 2003d). Dessa forma, se pensarmos na exígua 
quantidade de negros nas universidades, de fato uma propriedade “antidemocrática” pode ser inferida da situação atual.

Menezes (2003) promove interessante discussão sobre os perigos de se comparar juridicamente as decisões norte-americanas com as decisões brasileiras - como o fazem, muitas vezes, os contrários às cotas. Segundo ele, trata-se de “ordenamentos jurídicos" extremamente díspares, fato que torna leiga e incoerente uma comparação desavisada. Um dos aspectos que devem ser considerados é o fato de o Brasil, em seu Programa Nacional de Direitos Humanos (Presidência da República, 1996), prever ações afirmativas, a exemplo do favorecimento a deficientes físicos e às mulheres nas disputas eleitorais. Também deve ser considerada a participação do Brasil em tratados internacionais a favor de políticas de ação afirmativa, assim como a própria postura jurídica já assumida: “... a Constituição brasileira contempla diversas previsões que favorecem a adoção de tratamento diferenciado para os indivíduos da raça negra (ex. art. $3^{\circ}$, I, III e IV), iniciando-se pelo próprio preâmbulo da Carta, que reconhece 'a igualdade e a justiça como valores supremos de uma sociedade fraterna, pluralista e sem preconceito’” (Menezes, 2003).

Em relação aos argumentos de que as cotas seriam uma medida discriminatória, alguns autores afirmam que as cotas não são uma “discriminação às avessas”, mas sim, uma “discriminação positiva” (Conceição, 2002). Outra autora, Edna Roland (2002), discorda dos argumentos que consideram o sistema de cotas discriminatório e que implicam uma desconfiança na capacidade dos negros. Segundo a autora, não se duvida da capacidade do negro, mas tem-se certeza das "barreiras sociais concretas" que o impedem de possuir iguais oportunidades de acesso à Universidade.

\section{Esfera étnica}

A esfera de debate que ora apresentamos está radicada na discussão acerca do critério utilizado para se estabelecer quem é afrodescendente em um país como o Brasil, calcado na miscigenação.

Assim, os indivíduos que se apresentam contra as cotas aludem à sua impossibilidade de operacionalização em virtude da ausência de um critério "científico" para se determinar, sem brecha para fraudes, quem é realmente negro no Brasil.

Bernardes (2003) é um autor emblemático nessa posição. Ele lança mão de estudos realizados por geneticistas da UFMG (Universidade Federal de Minas Gerais) para defender a falta de precisão da cor e da aparência física para determinar a ascendência africana.

Em virtude de o termo "raça” não possuir um caráter científico, também essa evidência é utilizada como argumento para a impossibilidade de determinação étnica. A esse respeito, Chaves (2001), autor que faz alusão à miscigenação no Brasil como grande prova da "mais bem-sucedida integração racial do planeta”, pondera que o critério de "ascendência familiar" para determinar as cotas equivaleria, no Brasil, a um "medonho revival" de métodos nazistas para se determinar quem era ou não descendente de judeus (Chaves, 2001). Para a antropóloga Yvonne Maggie, o sistema de cotas criaria um "racismo de Estado" (Colombo, 2006).

Bernardes (2003) afirma que, embora a autonomeação seja um critério mais democrático, ela leva, inevitavelmente a fraudes. Para tanto, cita exemplos históricos nos quais esse critério não deu certo: louros australianos se declararam aborígines para possuírem direitos à terra; nos EUA, negros se inscrevem como índios para receberem indenizações reservadas aos primeiros. Esse 
Os cidadãos que se declaram a favor do sistema de cotas também possuem opiniões distintas sobre a maneira de se determinar quem é negro. mesmo raciocínio é difundido pela edição da Folha de São Paulo (23/08/01), que coloca o inconveniente de qualquer um se passar por negro para gozar do benefício das cotas. Para endossar tal argumento, algumas reportagens citam brancos que se inscreveram como negros somente para serem beneficiados com as cotas (JT, 02/06/03).

Dessa forma, dada a indefinição de um "método científico" para estabelecer quem participaria das cotas nas universidades, o sistema seria inviável. Para alguns indivíduos mais efusivos, o "regime de cotas em função da cor da pele revela oportunismo ou ignorância de quem a apóia, porque não existe 'raça' e nem a etimologia da palavra é conhecida”. Para Azevedo (2003), trata-se de um sistema "iníquo e inconstitucional" e "pura demagogia ignorante”.

Os cidadãos que se declaram a favor do sistema de cotas também possuem opiniões distintas sobre a maneira de se determinar quem é negro. No entanto, embora haja divergências, essas pessoas parecem pensar de forma semelhante a Jorge Werthein, representante da Unesco no Brasil, para quem a dificuldade de se adotar critérios bem definidos para saber quem é negro não invalida a proposta das cotas (Sato, 2003).

Edna Roland (2002) defende a "autodefinição", conforme critério estabelecido pelo IBGE; Lage (2003) expõe, em contrapartida, que o sistema de autodeclaração traz o inconveniente de o candidato faltar com a verdade somente para gozar do direito.

Em postura mais crítica, Domingues (2003) afirma que há um "discurso ideológico da mestiçagem”, segundo o qual todos são mestiços, já que não existe uma raça pura negra. Tal discurso, segundo o autor, favorece o fato de o brasileiro não se assumir como negro. Assim, o sistema de cotas viria favorecer a ruptura com essa "esquizofrenia" do nosso sistema racial, na medida em que obriga as pessoas a se assumirem como negras. Sobre as possíveis fraudes de pessoas brancas que se autodenominaram negras para serem beneficiadas com as cotas, Domingues afirma que se trata de "exceções", e que "não possuem importância na medida em que o autor adota um critério de definição para além da cor da pele". Tal critério, distinto dos anteriores, é o seguinte: "O meu critério é político e ideológico. Negro é quem se assume, quem se identifica enquanto tal, é todo aquele que abraça a luta anti-racista”.

Diante de tal variedade de opiniões, Martvs Chagas, secretário de Combate à Discriminação Racial do Partido dos Trabalhadores, não defende um critério único para a determinação da afro-descendência, porém fala da autodefinição como um processo mais “democrático” (O Estado de São Paulo, 16/02/03).

\section{Esfera político/assistencial}

Em tal esfera de debate, irrompe a discussão sobre políticas universalistas versus políticas específicas. Assim, são discutidas diversas formas e estratégias públicas, a curto, médio e longo prazos, cuja finalidade é proporcionar a democratização do ingresso no ensino superior.

Os indivíduos que se expressam contra o sistema de cotas afirmam que se deve combater as desigualdades sociais, e não as desigualdades raciais (Menezes, 2003; O Estado de São Paulo, 23/06/03), posto que, como pondera Cristovam Buarque, há um "preconceito de classe" mais forte que o preconceito racial (Sato, 2003). Por conseguinte, defendem medidas que visem à melhoria da qualidade do ensino fundamental e médio da escola pública, única intervenção capaz de, realmente, criar o ingresso 
democrático nas universidades públicas. Assim, propaga-se a idéia de que são as disparidades socioeconômicas, e não as raciais, que estariam no cerne do problema, sendo inócuas as cotas para negros.

Nesse sentido, o sistema de cotas é criticado por constituir um “atalho”, pois desvia o problema da qualidade do ensino básico, considerada a verdadeira causa do fracasso escolar do negro (Fernandes, 2003).

Reiko Niimi, representante do Fundo das Nações Unidas para a Infância (Unicef) no Brasil, é contra as cotas, pois, no seu entender, elas não são eficazes no combate às desigualdades. Argumenta que os esforços devem se voltar para as primeiras fases escolares. A opinião da representante é emitida mesmo tendo em vista o relatório da Unicef, que comprova haver mais crianças negras fora da escola em relação às brancas (idade de quatro a seis anos), e que crianças negras possuem riscos duas vezes maiores de residirem em domicílios sem água, se comparadas com crianças brancas (Formenti, 2003).

Os autores favoráveis às cotas afirmam, em sua grande maioria, que se deve ter em mente que as mesmas não anulam, mas sim, andam aliadas à melhoria no ensino médio e fundamental da escola pública. Assim, as cotas para negros seriam defendidas como "políticas específicas”, pela constatação de que, no Brasil, “a pobreza tem cor”, ou seja, a população afro-descendente estaria mais lesada, mesmo se comparada com populações brancas do mesmo nível socioeconômico. Outrossim, a política de cotas seria uma medida transitória e imediatista, necessária enquanto não são realizadas melhorias no ensino médio. Domingues (2003), Vogt (2003) e Conceição (2002) são autores emblemáticos nessa argumentação.

Para Jorge Werthein, representante da Unesco no Brasil (Sato, 2003), e para o professor do Instituto de Economia da UFRJ, Marcelo Paixão (Folha de São Paulo, 06/01/02), conceber que o sistema de cotas seja anulado pela necessidade de se fortalecer o ensino público seria uma forma de postergar o problema por algumas décadas, pois os jovens negros atuais continuariam “à parte” da medida universalista. Nesse sentido, Luiz Felipe De Alencastro (Folha de São Paulo, 09/07/2006) não acredita que “a universalização e qualificação do ensino sejam suficientes para mudar as injustiças históricas”.

Em contraposição ao parecer de que a contundente desigualdade social seria a determinante da desigualdade racial, são vários os autores que defendem a incoerência de tal constatação. Em sua grande maioria, falam do desfavorecimento do negro em relação ao branco mesmo quando ambos possuem condições socioeconômicas semelhantes. Nesse sentido, Edna Roland apresenta evidências das distinções entre negros e brancos referentes ao IDH e à dificuldade de inserção no mercado de trabalho (Souza, 2003b); Góis (2003) lança mão de pesquisas que evidenciam que alunos negros possuem menores notas que alunos brancos; Rose Neubauer conclui, em pesquisa na Fundação Carlos Chagas, a ocorrência de pouca expectativa e atenção dos professores em relação aos alunos negros, e Ana Maria Popovic, em pesquisa realizada nos anos 80 , verificou que crianças negras possuíam menor autoestima em relação às brancas (Góis, 2003).

Enfim, pode-se afirmar que, para esses autores, há uma coincidência da pobreza com a população afro-descendente, simbolizada na frase emblemática de que, no Brasil, a “pobreza tem cor” (O Estado de São Paulo, 16/02/03).

A favor da política específica para o afrodescendente, Domingues (2003) afirma que algumas políticas governamentais universalistas “... resultaram na melhoria do nível educacional do brasileiro de um modo geral, mas a taxa de desigualdade entre negros e brancos permanece inalterada”. 


\section{Esfera ideológica}

A esfera ideológica de debate, na acepção aqui adotada, discute o critério do "mérito pessoal" como inerente ao ingresso dos alunos nas universidades via vestibular.

A reportagem de Fernandes (2003) para a revista Época registra uma situação emblemática. Compara duas estudantes que cursaram a mesma escola particular do Rio de Janeiro, porém uma era negra, e a outra, branca. A estudante negra tirou uma pontuação muito inferior à da branca, mas foi aprovada, ao contrário da branca.

Assim, muitos autores refutam o sistema de cotas, pois o mesmo interfere nesse critério considerado inalienável (Souza, 2003d; Folha de São Paulo, 11/02/03). Consideram, ainda, que qualquer critério que interfira no mérito pessoal estará cometendo factível injustiça (Folha de São Paulo, 23/08/01).

Menezes (2003) argumenta que as desvantagens sofridas por determinado grupo variam de acordo com cada indivíduo. Uma ação que beneficie todo o grupo acaba por favorecer pessoas que não necessitam do benefício.

Em suma, fala-se em uma "ideologia cotista" que apresenta uma visão "racista", pois negligencia "fatos comprovados da realidade", quais sejam, de "que negros e pardos têm condições de vencer, plenamente, em todos os campos da atividade humana, graças a seus próprios méritos e esforços, sem que, para isso, necessitem de 'vantagens' compensatórias" (O Estado de São Paulo, 23/06/03).

Alguns afro-descendentes, numa posição contrária às cotas, dão a entender que ela reduziria o mérito pessoal das pessoas que conseguiram alcançar seus objetivos sem ser favorecidas. Carla, negra e universitária, afirma que abomina as cotas, pois sua "vitória pessoal", fruto de dedicação durante toda a vida, seria reduzida ao confundirem-na como beneficiária de uma "vantagem" concedida legalmente (Carneiro, 2003).

Contra a ideologia do mérito e a favor das cotas, Carneiro escreve:

“A postura da leitora (refere-se ao depoimento de Carla - adendo nosso) demonstra a eficiência dos mecanismos educativos e ideológicos de nossa sociedade para inculcar-nos a visão segundo a qual a mobilidade social está aí, disponível igualitariamente a todos, dependendo apenas do esforço pessoal de cada um para a sua realização. Desaparecem, assim, as condições históricas que vêm produzindo e reproduzindo a pobreza dos negros. Então, os excluídos, de vítimas, tornam-se réus. Nessa armadilha em que o individualismo liberal nos enreda, a mobilidade social individual de uma pessoa negra é utilizada contra o próprio grupo racial, reiterando os estigmas que o afligem. $\mathrm{O}$ negro "bem sucedido" torna-se a exceção que confirma a regra discriminatória: se um consegue, os demais não se esforçaram o suficiente (2003)”.

Sobre a opinião de que as cotas "desqualificam" o negro, Carneiro defende a idéia de que, pelo contrário, elas consagram o negro como sujeito histórico portador e consciente de seus direitos enquanto cidadão.

Domingues (2003) também associa a questão do mérito a um "discurso ideológico" dissimulador da inserção do negro em um contexto sociohistórico que o coloca em situação de desvantagem para competir em pé de igualdade com o branco: "Em uma sociedade capitalista e racista, as oportunidades na vida não são igualitárias”.

Assim, até meios de comunicação de massa explicitamente contra as cotas reconhecem a inverossimilhança de aventar o mérito pessoal como justo em sociedades que são reconhecidamente preconceituosas. O editorial de O Estado de São Paulo (29/06/03) destaca 
que seria uma falácia propagar a igualdade da meritocracia, pois os negros estariam em situação de desvantagem no sistema competitivo por mérito.

Contrapondo-se a prerrogativa de que alunos negros de escolas particulares se beneficiariam das cotas, Marcelo Paixão pondera que não há problema, pois, mesmo estudando nas melhores escolas, o negro sofre nestas o racismo e, depois de sua formação, seus rendimentos são afetados (Folha de São Paulo, 06/01/02).

Por fim, contrariando a idéia de injustiça das cotas, Edna Roland afirma que o vestibular atual não mede o "mérito do candidato", mas sim, a qualidade do ensino e as condições de estudo que recebeu na vida: "o vestibular mede principalmente o mérito do sistema escolar, das condições sociais e a desigualdade de oportunidades". Assim, o sistema de cotas, ao estabelecer a competição entre pessoas que possuem as mesmas oportunidades, seria mais igualitário para medir o "mérito do estudante", e não o mérito das oportunidades que recebeu (Roland, 2002).

\section{Esfera pedagógica}

As conseqüências educacionais geradas pela inserção dos alunos afro-descendentes cotistas nas universidades públicas permeiam a esfera pedagógica do debate. Em seu interior, estão idéias de que a referida inserção traria uma queda na qualidade do ensino nessas instituições (Lage, 2003), seja porque os universitários negros possuiriam maior dificuldade de aprendizagem devido à cumulação de déficits provenientes do ensino médio e fundamental, seja porque a medida poderia gerar maior evasão escolar (Folha de São Paulo, 11/02/03), ou mesmo, em opinião mais veemente, ocorreria uma inevitável aprovação compulsiva desses alunos, mesmo que eles não apresentem o grau de competência habitualmente exigido. Fala-se até em uma "inevitável” aprovação compulsória, "na medida em que essas ações estão sendo motivadas pela política de grupos militantes, e que o próximo e inevitável passo será pressionar os professores para que aprovem tais alunos "carentes" ou "coloridos", embora sem atender aos níveis habituais de competência” (Lage, 2003).

Dessa forma, coloca-se, como um dos empecilhos, o fato de os beneficiados pelas cotas necessitarem de matérias introdutórias e aulas de reforço para acompanhar os cursos (Jornal da Tarde, 02/06/03).

Quanto à necessidade de pequenas modificações no âmbito dos cursos oferecidos pelas universidades, muitos defensores do sistema de cotas afirmam haver uma adaptação dos alunos em relação à Universidade, o que não gera dificuldade alguma de acompanhamento dos cursos. Tais adaptações assumem a forma de "aulas de reforço", segundo a opinião de Edna Roland (Souza, 2003b); "programa de apoio" e "disciplinas instrumentais”, no ponto de vista de Nilcéa Freire, reitora da UERJ (Jornal da Tarde, 16/02/03).

Frei Davi dos Santos, coordenador da Educafro, ONG que mantém uma rede de noventa e quatro pré-vestibulares comunitários, sugere que tais medidas seriam suficientes para que os negros tivessem uma formação equivalente à dos brancos. Comenta o caso de um advogado do cursinho da Educafro que entrou na última chamada, e, quando formado, estava entre os dez melhores alunos da turma (Jornal da Tarde, 16/02/03).

Contra o argumento de rebaixamento da qualidade de ensino, Domingues (2003) afirma: "Ora, não basta ser negro para, automaticamente, ser aprovado nesse novo mecanismo de seleção. Tem que ter qualificação". Nesse sentido, Gois e Gomide (2006) ressaltam que as políticas de ação afirmativa em discussão no Congresso já podem ser avaliadas, tendo como base experiências concretas que se dão em várias universidades públicas brasileiras. A partir de análises dos efeitos das políticas adotadas pela Universidade Federal da Bahia, pela Universidade Estadual de Campinas e pela Universidade Estadual do Rio Grande do Sul, concluem que o 
desempenho dos beneficiados foi semelhante e, em alguns casos, até superior aos demais estudantes, além das taxas de evasão dos cotistas serem menores.

Na mesma direção, argumenta-se que o ingresso de negros nas universidades traria, ainda, diversas vantagens ao ambiente acadêmico. Segundo Edna Roland (2002), haveria um enriquecimento do ensino, pois teríamos a oportunidade de conviver com a diversidade cultural e a participação criativa de grande parcela da população brasileira. O advogado John Payton afirma que, no início, a adoção de cotas causou contestações dos alunos brancos norte-americanos, mas, posteriormente, todos reconheceram a melhoria do ensino em virtude da integração racial (2003d). A Suprema Corte desse mesmo país considera a raça como um dos critérios utilizados para o ingresso na Universidade, pois traria uma diversidade favorável à construção de um ambiente educacional mais fecundo (O Estado de São Paulo, 29/06/03).

\section{Esfera das relações raciais}

No âmbito dessa esfera, observa-se a discussão sobre as modificações nas relações raciais entre negros e brancos que decorrem do sistema de cotas. A repercussão ética, nessas relações, apresenta-se como um dos motivos para alguns afirmarem que essa política seria prejudicial e, portanto, justificarem a anulação das cotas, mas outros consideram-na positiva, tendo em vista o fato de que ela favorece o rompimento com a falácia da democracia racial, presente na constituição histórica do Brasil.

Alguns autores contrários às cotas argumentam que sua implantação dificulta a integração dos afro-descendentes na sociedade brasileira, na medida em que promove um aumento da discriminação racial, que pode culminar em “ódio racial” (Jornal da Tarde, 02/06/03), no "ressentimento" entre grupos raciais (Fernandes, 2003), o que constitui um "perigoso estímulo ao preconceito" (Chaves, 2001) e promove a estigmatização dos negros nas universidades (Menezes, 2003). Para Rosenfield (2006), a implantação do sistema de cotas pode provocar "novos conflitos que o País poderia muito bem poupar”.

Fernandes (2003), ao avaliar o funcionamento das cotas na experiência do Rio de Janeiro, faz alusão a um "ambiente estranho" entre os estudantes, explícito a partir da difusão de panfletos anônimos altamente discriminatórios para com os negros. Cabe ressaltar que, para esse autor, o Brasil é um país sem "tensões raciais”, e, com a implantação das cotas, essa harmonia poderia ser rompida.

Longe de propor a minimização do confronto entre negros e brancos, Domingues (2003) afirma que a implementação e a discussão sobre o sistema de cotas seriam absolutamente positivos para o Brasil, no sentido de "implodir" "as bases ideológicas de sustentação do mito da democracia racial”, o que romperia, pela primeira vez na história brasileira, com o silêncio em relação ao racismo. Em sua opinião, com as cotas, o que pode ocorrer é "cair a máscara do racismo na sociedade brasileira", colocando-o de forma explícita, e não, dissimulada e velada, como tem existido através dos tempos. Por fim, Domingues assevera que, no conflito entre negros e brancos, que, para muitos, constitui um empecilho para a implementação das cotas, reside o início da superação desses mesmos conflitos raciais: "Portanto, o racismo à brasileira já é perverso; porém, se o programa de cotas contribuir para que o conflito nas relações raciais fique declarado, vai ser o primeiro passo para a sua superação definitiva” (Domingues, 2003).

\section{Considerações finais}

Ao final deste percurso, retornamos a seu início: o debate sobre as cotas e a questão da subjetividade do afro-descendente nele implicado. Em meio à complexidade das discussões nas diversas esferas mencionadas, o debate sobre as cotas parece estar movido pela contradição entre os argumentos a favor e contra o sistema de cotas. Observamos, assim, que todo o debate sobre as questões raciais no Brasil 
atualmente está vivo. Todo o passado histórico se revela ainda atual. Não mais silêncio. A pretensa harmonia representada na idéia de democracia racial é denunciada. Configura-se a discussão de forma desnuda: no debate aberto, com suas contradições à flor da pele.

Nesse contexto, a “naturalização” da desigualdade racial é questionada pela discussão sobre os processos sociais implicados na construção da identidade do afro-descendente no Brasil.

Discursos diversos, opiniões distintas: eis a mola propulsora dos debates. Negação da diferença, discriminação do diferente, subalternização e inferiorização daquele que é ou pensa diferente, eis a tônica que movimenta os diversos argüidores do debate sobre as cotas. Cada qual orienta seu argumento de forma a tornar o argumento de seu opositor ignóbil, infundado, incoerente, inverossímil.

Entretanto, em nossa opinião, o respeito à diferença e o incentivo à livre manifestação das diversidades deveriam ser os objetivos últimos de qualquer movimento social voltado para o afro-descendente. Logo, qualquer postura absolutista, totalizante, que renega a legitimidade e a manifestação de opiniões diversas, deve ser revista, pois reproduz justamente aquilo que critica: o preconceito ao diferente.

Ora, como caminha o conhecimento senão pela contradição das idéias? Como constituímos nossas identidades, senão pela relação com os outros diferentes de nós?

Conforme Ferreira (2000), o afro-descendente, como qualquer pessoa, desenvolve sua identidade articulado aos valores socialmente associados a seu grupo de pertencimento, numa relação dialética entre o indivíduo e a sociedade como um todo. No caso da pessoa negra, são valores associados às suas condições de vida, como apontamos na discussão sobre as condições de vida do afro-descendente, no item 3. Assim, podemos concluir que o afro- brasileiro tende a desenvolver uma identidade organizada em torno de referências consideradas de menor valor, como suas situações concretas de vida o são, o que favorece atitudes de submissão aos valores hegemônicos brancos.

É possível, entretanto, a superação dessa atitude, principalmente através de situações de impacto, de experiências que neguem essas referências, o que impeliria as pessoas à transformação de seus valores e de sua subjetividade, fator necessário para mudanças efetivas nas suas condições de vida.

Nesse sentido, longe de vermos o atual debate como premonitório de ódios raciais, observamos a atual situação como uma situação de impacto, como uma crise que não deve ser concebida como destrutiva, mas sim, como ensejo prenhe de uma transformação, de um horizonte qualitativamente distinto acerca das relações raciais. $\mathrm{O}$ acirramento dos debates culmina na crise que gera nova organização das idéias, a re-invenção das representações sobre os afro-brasileiros.

Tal disposição geral dos debates sobre as cotas manifesta-se nas subjetividades particulares. Em outras palavras, todos os brasileiros, sejam brancos ou negros, são impelidos a posicionarse e a adentrar o âmago dessas contradições. Trata-se de condições propícias para os afrodescendentes vivenciarem também uma crise que os leva a refletir sobre quem foram seus antepassados, quais as suas condições atuais e como serão suas perspectivas de futuro. Via de regra, o posicionamento no cerne dos debates faz com que venham a possuir uma visão mais crítica sobre as desigualdades raciais, rompendo com a visão de que as diferenças são naturais, o que implica uma ruptura com a re-produção da ideologia da "democracia racial" que se manifesta no âmbito individual, como submissão aos valores brancos e negação das origens africanas. $\mathrm{O}$ vivenciar essa crise pode gerar a ruptura com uma posição de submissão do afro-descendente aos valores vigentes, em 
relação aos quais se sente desvalorizado como pessoa, e pode fazer com que ele se torne, como sujeito histórico que é, autor de transformação da realidade social à qual está submetido.

Finalizando, queremos ressaltar que não buscamos respostas conclusivas. Isso nos levaria a uma direção que consideramos nociva - a desqualificação de outras opiniões que não as nossas, e reproduziria justamente aquilo de que discordamos: o preconceito com o diferente.

Assim, algumas questões permanecem: a política de cotas poderá ser favorável ou não para a melhoria das condições de vida dos brasileiros negros, apesar das dificuldades que dela podem advir? Poderá auxiliar na construção de identidades negras positivamente afirmadas? Pode ser considerada uma das estratégias para favorecer a ruptura do círculo vicioso ao qual o afro-descendente está submetido: pobreza, falta de condições educacionais, condições precárias de trabalho, status social considerado inferior e identidade submetida a referências de menor valor?

Convidamos o leitor, a partir de nossas considerações, a se posicionar, a tirar suas próprias conclusões e entrar nesse debate.

\section{Ricardo Franklin Ferreira}

Doutor em Psicologia Escolar e do Desenvolvimento Humano; ex-coordenador e docente do Programa de Pós-Graduação em Psicologia da Universidade São Marcos

Ricardo Mendes Mattos

Mestre em Psicologia pela Universidade São Marcos

Rua: Loefgreen, 359, ap. 81. Vila Clementino, São Paulo, SP CEP 04040-030

Te.: (11) 3491-0522; 7626-9012

E-mails: ricardo_franklin@uol.com.br - ricardomendesmattos@ig.com.br

BENTO, Maria Aparecida Silva. Cidadania em Preto e Branco. São Paulo: Ática, 2000

BERGER, Peter L. \& LUCKMANN. Thomas. A Construção Social da Realidade. Tratado de Sociologia do Conhecimento. $17^{\mathrm{a}}$ ed. Petrópolis - RJ: Vozes, 1999.

BERNARDINO, Joaze. Ação Afirmativa e a Rediscussão do Mito da Democracia Racial no Brasil. Estudos Afro-Asiáticos, 24, 2, pp. 247-273, 2002.

D’ADESKY, Jacques. Pluralismo Étnico e Multiculturalismo: Racismos e Anti-racismos no Brasil. Tese de doutorado em Antropologia. Universidade de São Paulo, São Paulo, 1996.

DIEESE - Departamento Intersindical de Estatísticas e Estudos SócioEconômicos; Instituto Sindical Interamericano pela Igualdade Racial; Centro de Solidariedade AFL-CIO. Mapa da População Negra no Mercado de Trabalho. São Paulo: 1999, 134 p.
FERREIRA, Ricardo Franklin. Afro-descendente: Identidade em Construção. São Paulo, EDUC/ Rio de Janeiro: Pallas, 2000.

O Brasileiro, o Racismo Silencioso e a Emancipação do Afro-descendente. Psicologia \& Sociedade, 14, 1, pp. 69-86, 2002.

FERREIRA, Ricardo Franklin \& CAMARGO, Amilton Carlos. A Naturalização do Preconceito na Formação da Identidade do Afrodescendente. ECCOS - Revista Científica, 1, 3, pp. 75-92, 2001.

GUARESCHI, Pedrinho. Psicologia Social Crítica como Prática de Libertação. Porto Alegre: EDIPUCRS, 2004.

JODELET, Denise. Representações Sociais: um Domínio em Expansão. In: Jodelet, Denise. (org.). As Representações Sociais. Rio de Janeiro: Ed. UERJ, 2001, pp. 17-44. 
LARKIN NASCIMENTO, Elisa . O Sortilégio da Cor. Identidade, Raça e Gênero no Brasil. São Paulo: Summus, 2003.

MOEHLECKE, Sabrina. Ação Afirmativa: História e Debates no Brasil. Cadernos de Pesquisa, 32, 117, pp. 197-217, 2002.

MOURA, Clóvis. Sociologia do Negro Brasileiro. São Paulo: Editora Ática, 1988.

MUNANGA, Kabengele. Rediscutindo a Mestiçagem no Brasil. Identidade Nacional versus Identidade Negra. Rio de Janeiro: Vozes, 1999

PAIM, Paulo. Estatuto da Igualdade Racial. Brasília: Senado Federal, 2003.

PRESIDÊNCIA DA REPÚBLICA. Programa Nacional de Direitos Humanos. Fernando Henrique Cardoso. Brasília: Secretaria de Comunicação Social, Ministério da Justiça, 1996.

SANTOS, Hélio. ABusca de um Caminho para o Brasil: a Trilha do Círculo Vicioso. São Paulo: Editora SENAC, São Paulo, 2001.

SOUZA, Irene Sales de. O Resgate da Identidade na Travessia do Movimento Negro: Arte, Cultura e Política. Tese de doutorado. Instituto de Psicologia-Universidade de São Paulo-SP, 1991, 376 p.

SUPLICY, Eduardo Matarazzo. Renda de Cidadania: a Saída é pela Porta. São Paulo: Cortez, 2002.

TELLES, Edward. Racismo à Brasileira. Uma Nova Perspectiva Sociológica. Rio de Janeiro: Relume Dumará - Fundação Ford, 2003.

Artigos jornalísticos utilizados como fonte de dados AZEVEDO, José Carlos. Efeitos perversos. Universia Brasil, 27 fev. 2003. Artigo disponivel na internet: http://www.universiabrasil.net/portada/ actualidad/noticia_actualidad.jsp?noticia=37008 [28/02/2003]

BERNARDES, Ernesto. A lógica de Torquemada. Revista Época. São Paulo. Seção de Educação, p. 38, 17 fev. 2003.

CARNEIRO, Sueli. Nós? Especial “A polêmica das cotas”. Correio Braziliense, 28 fev. 2002. Artigo disponível na internet: www.afirma.inf.br [01/04/2003].

CHAVES, Mauro. Aviltante discriminação social. O Estado de São Paulo, São Paulo, 15 dez. 2001. Artigo disponível na internet: http://www.estado.com.br/editorias/2001/12/15/aberto002.htm [17/02/2003].

COLOMBO, Sylvia. Estatuto criaria "racismo de Estado", diz antropóloga. Folha de São Paulo, São Paulo. Cotidiano. 23 jul. 2006. Artigo disponível na internet: http://www1.folha.uol.com.br/fsp/ cotidian/ff2307200614.htm [26/07/2006].

CONCEIÇÃO, Fernando. Cotas e o “jus sperniandi”. Folha de São Paulo, São Paulo, 02 dez. 2002, p. A3.

DOMINGUES, Petrônio José. Chega de esperar: Cotas para negro já! Revista Espaço Acadêmico, ano III, n ${ }^{\circ} 27$, agosto de 2003. Artigo disponível na internet: http://www.espacoacademico.com.br/027/ 27cdomingues.htm [17/02/2004]

FERNANDES, Nelito. Começo errado. Revista Época. Rio de Janeiro, seção de Educação, pp. 34-37, 17 fev. 2003.

FOLHA DE SÃO PAULO. Cotas de racismo. São Paulo, 23 ago. 2001 p. A2.

FOLHA DE SÃO PAULO. Economista defende cotas para negros. São Paulo, 06 jan. 2002, p. C3.

FOLHADE SÃO PAULO. Cotas e nada mais. São Paulo, 11 fev. 2003, p. A2.

FOLHADE SÃO PAULO. Confira a íntegra dos manifestos contra e a favor das cotas. 04 de jul. 2006. Artigo disponível na internet: http//www1.folha.uol.com.br/folha/educaao/ult305u18773.shtm [26/07/2006].

FOLHA DE SÃO PAULO. “A divisão já existe, está escrita na nossa sociedade”, diz Luiz Felipe de Alencastro. Revista Mais, 09 jul. 2006. Artigo disponível na internet: http://www1.folha.uol.com.br/fsp/ mais/fs0907200609.htm [26/07/2006].

FORMENTI, Lígia. ONU questiona eficiência de cotas e bolsa-escola. O Estado de São Paulo, São Paulo, 25 jun. 2003. Artigo disponível na internet:

http://www.estadao.com.br/agestado/noticias/2003/jun/25/ 229.htm [12/08/2003].

GOIS, Antônio. Preconceito afeta desempenho na escola. Folha de São Paulo. São Paulo, 18 mai. 2003, p. C5.
GOIS, Antônio \& GOMIDE, Raphael. Estudos apontam bom rendimento de cotistas. Folha de São Paulo, São Paulo, Cotidiano, 23 jul. 2006. Artigo disponível na internet: http// www1.folha.uol.com.br/fsp/cotidian/ff230720063.htm [26/07/ 2006].

JORNAL DA TARDE. Ministro apoiava a idéia. Hoje, defende o consenso. São Paulo, 16 fev. 2003. Artigo disponível na internet: http://www.jt.estadao.com.br/editorias/ 2003/02/16/ger022.html [17/02/2003]

JORNAL DA TARDE. A demagogia das cotas chegou a SP. São Paulo, 02 jun. 2003. Artigo disponível na internet: http// www.jt.estadao.com.br/editorias/2003/06/02/Ger 003.html [12/ 08/2003].

LAGE, Nilson. Educação e a política de cotas. Observatório da Imprensa, $n^{\circ}$ 215, 18 mar. 2003. Artigo disponível na internet: http://observatorio.ultimosegundo.ig.com.br/cadernos/ cid120320031.htm [01/04/2003].

MANIFESTOEMFAVORDA LEIDECOTASE DOESTATUTODA IGUALDADE RACIAL 03/07/2006. Artigo disponível na internet: www.rolim.com.br/2002/_pdfs/100706.pdf [08/08/2006].

MENEZES, Paulo Lucena de. As políticas de ação afirmativa e a questão racial. Especial “A polêmica das cotas”. Sindicato dos Professores de São Paulo - SINPRO, 18 mar. 2003. Artigo disponível na internet: http://www.sinprosp.org.br/especiais/ especial_18032003/3html [01/04/2003].

OESTADO DE SÃO PAULO. Cotas são medidas amargas de transição. São Paulo, 16 fev. 2003. Artigo disponível na internet: http://www.estado.estadao.com.br/editorias/2003/02/16 ger009.html [17/02/2003]

O ESTADO DE SÃO PAULO. As cotas inconstitucionais. São Paulo, 23 jun. 2003. Artigo disponível na internet: http:// txt.estado.com br/editorias/03/06/23/editoriais001.htm [30/07/2004].

O ESTADO DE SÃO PAULO. O endosso à ação afirmativa nos EUA. São Paulo, 29 jun. 2003. Artigo disponível na internet: http:// www.estado.com.br/editorias/2003/06/ 29/editoriais002.html [12/08/2003].

PAIXÃO, Marcelo. IDH de negros e brancos no Brasil em 2001: e a desigualdade continua! Com Ciência: Revista Eletrônica de Jornalismo Científico. Universidade Estadual de Campinas, 2003. Artigo disponível na internet:

http://www.comciencia.br/reportagens/negros/12.shtml [11/04/ 2004].

ROLAND, Edna. Cotas para promover a igualdade. Folha de São Paulo. São Paulo, 23 mai. 2002. Caderno FOVEST, p. 5.

ROSENFIELD, Denis Lerrer. Novos conflitos. Folha de São Paulo. São Paulo, Opinião, 29 abr. 2006. Artigo disponível na internet: http://www1.folha.uol.com.br/fsp/opiniao/fz2904200610.htm [26/07/2006].

SATO, Sandra. Cotas para negros não resolvem a desigualdade, diz ministro da Educação. O Estado de São Paulo. São Paulo, 18 fev. 2003. Artigo disponivel na inter educando/noticias/2003/fev/18/226htm [17/02/2003].

SOUZA, Marcos de Moura e. Como resolver uma dívida que dura séculos. O Estado de São Paulo. São Paulo, 16 fev. 2003a. Artigo disponível na internet: http://www.estado.estadao.com.br/ editorias/2003/02/16/ger013.htm

[17/02/2003].

SOUZA, Marcos de Moura e. Opiniões divididas mesmo entre os favorecidos. O Estado de São Paulo. São Paulo, 16 fev. 2003b, Geral, p. 14.

SOUZA, Marcos de Moura e. SP abre discussão sobre as cotas em universidades. O Estado de São Paulo. São Paulo, 10 mai. 2003c. Artigo disponível na internet: http://www.estado.estadao.com.br/ editorias/2003/05/10/ger016. html [12/05/2003].

SOUZA, Marcos de Moura e. Ação afirmativa melhorou o ensino. 0 Estado de São Paulo. São Paulo, 29 jun. 2003d.

Artigo disponível na internet: http://www.estado.com.br/editorias/ 2003/06/29/ger018.html [12/08/2003].

TODOS TÊMDIREITOS IGUAIS NA REPÚBLICADEMOCRÁTICA Artigo disponível na internet: http://www.geocities.com/ cartapublica2006/ [08/08/2006]

VOGT, Carlos. O papel estratégico das cotas. Folha de São Paulo. São Paulo, 07 mar. 2003, p. A3. 